Parallel Processing of Atmospheric Chemistry Calculations: Preliminary Considerations

Scott Elliott

Philip Jones 


\section{DISCLAIMER}

This report was prepared as an account of work sponsored by an agency of the United States Government. Neither the United States Government nor any agency thereof, nor any of their employees, make any warranty, express or implied, or assumes any legal liability or responsibility for the accuracy, completeness, or usefulness of any information, apparatus, product, or process disclosed, or represents that its use would not infringe privately owned rights. Reference herein to any specific commercial product, process, or service by trade name, trademark, manufacturer, or otherwise does not necessarily constitute or imply its endorsement, recommendation, or favoring by the United States Government or any agency thereof. The views and opinions of authors expressed herein do not necessarily state or reflect those of the United States Government or any agency thereof. 


\section{DISCLAIMER}

Portions of this document may be illegible in electronic image products. Images are produced from the best available original document. 


\section{TABLE OF CONTENTS}

ABSTRACT

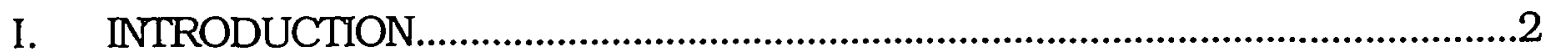

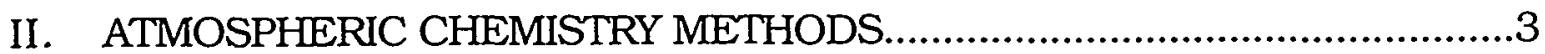

A. Individual Species Continuity Equations.................................................

B. Multiple Species Continuity Equations...................................................5

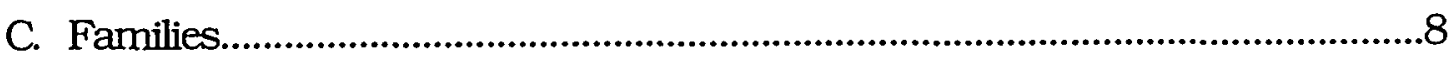

III. MASSIVELY PARALLEL COMPUTING OF CHEMISTRY.......................12

A. Machine Architectures............................................................................13

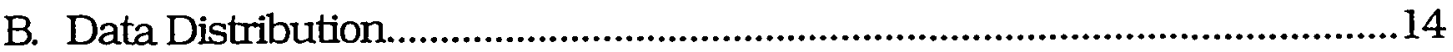

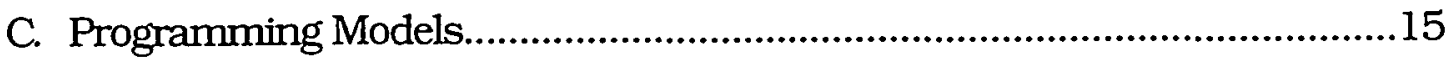

D. Parallel GCMs.........................................................................................16

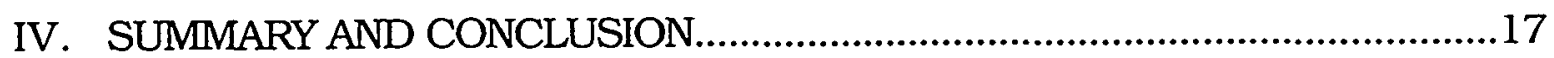

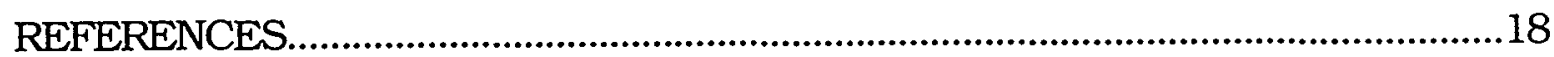




\title{
PARALLEL PROCESSING OF ATMOSPHERIC CHEMISTRY CALCULATIONS: PRELIMINARY CONSIDERATIONS
}

by

Scott Elliott and Philip Jones

\begin{abstract}
Massively parallel computing will be required for GCM simulations as resolutions near the one degree level and especially as chemically interacting tracers are added. Parallelization of the major climate and dynamics components of GCM programs is already underway. Here we explore the application of multiple processors to problems involving global atmospheric chemistry. In the time split mode, chemistry calculations are nearest neighbor independent, and great flexibility exists in distributing elements of the physical grid. Kinetics mechanisms are highly uncertain, however, so that setup of the chemical continuity equations must be automated. This requires short array dimensions over and above the physical, including species and reaction indices. Since climate calculations are tightly coupled in the vertical through radiative transfer, on parallel machines they are often decomposed by horizontal section. Such a decomposition is also ideal for chemistry as it provides flexibility for kinetics calculations and allows for easy incorporation into existing GCM models.
\end{abstract}




\section{INTRODUCTION}

Modern general circulation models (GCMs) push vector supercomputers to their computational limits. The physical grid representing the global terrestrial atmosphere or ocean may contain hundreds of thousands or even million of cells (Pitcher et al. 1983; Malone et al., 1986; Mahlman and Umscheid, 1987), while the realities of global change demand decadal scale simulations (Houghton et al, 1990 and 1992; Cess et al., 1993). Low processor number vector machines, however, have maximum efficiencies on the order of hundreds of megaflops (Levesque and Williamson 1989). A natural transition of GCMs to massively parallel computers has recently begun in order to exploit the potential for order of magnitude speedups (Smith et al., 1992; Dukowicz et al. 1993).

The atmospheric photochemical system is intimately coupled to climate and circulation through trace species such as ozone and methane (Fishman et al., 1979: Ramanathan and Dickinson, 1979; Crutzen, 1988; Houghton et a!., 1990 and 1992). Ultimately, interactive chemical GCMs will be required to complete understanding of climate, at the very least to provide self-consistent prognosis. There could conceivably be significant chemistry-to-climate feedback loops to be quantified (Ramanathan et al. 1987: Crutzen, 1988). Where climate models now incorporate only a handful of major atmospheric tracers such as water vapor (Ramanathan, 1988), a chemical GCM must track dozens of kinetically active groups of species (Crutzen. 1988; Brasseur et al. 1990: Kao et al., 1990: Singh and Zimmerman, 1992; Thompson, 1992). The need for parallel processing will be accentuated on a relative basis.

Parallel approaches to atmospheric chemistry calculations have been discussed in several previous works (Boris and Winsor, 1982; Elliott et al.. 1993 a through d). often from a vector computer perspective. We are preparing to place atmospheric chemistry modules into global tracer coding. and most particularly into GCMs, on massively parallel processors (MPPs). The current work provides some background information necessary for the design of optimized MPP chemistry coding. Much of the presentation will be generalizable to MPP machines of all makes. Several tracer transport frameworks may be available to us for dispersing our interacting chemical species, including the Geophysical Fluid Dynamics Laboratory Skyhi GCM (Mahlman and Moxim, 1977; Fels et al., 1980, Andrews et al.. 1985; Miyahara et al., 1985: Mahlman and Umscheid, 1987) and a global Chemical Tracer Model (CTM) adapting a positive definite advection scheme to isentropic coordinates (Smolarkiewicz, 1984; Margolin and Smolarkiewicz, 1989; Smolarkiewicz and Margolin, 1993).

Our discussion is aimed primarily at the atmospheric chemical modelling audience. For this reason we make almost no assumptions regarding prior knowledge of supercomputer architectures. In fact, we begin in almost all cases with very fundamental models of vector and parallel operations. introducing more sophisticated notions only as needed. The constructs have already proven pedagogically useful to S. E., who is an atmospheric chemist by training. 
The text is structured as follows. We begin by reviewing numerical methods of large scale chemical modelling with particular emphasis on fast kinetics integrators the authors have developed specifically for global three dimensional work (Elliott et al., 1993 a though d). Even these will demand MPP approches. A general theme emerges concerning the atmospheric chemistry; it is largely grid cell internal and so is naturally parallel. Next we introduce some parallel processing concepts and problems that parallel processing machines create for chemistry calculations. We identify optimal data distribution strategies incorporating techniques for automation of kinetics calculations. We also examine how atmospheric chemistry can be iniplemented within existing parallel programming models and how chemistry can be incorporated into existing parallel GCM's.

\section{ATMOSPHERIC CHEMISTRY METHODS}

In order to facilitate study of the photochemistry of climate, GCMs will soon enfold atmospheric kinetics; they will constitute what we will call chemical climate models (Kao et al., 1990: Elliott et al. 1993a). Typical GCMs today hold about 100,000 cells; $\sim 100 \times 100$ in the horizontal by $\sim$ ten in the vertical (Mahlman and Moxim, 1978; Pitcher et al. 1983; Kao et al., 1990). The transport time step is generally around one hour (Toon et al., 1988; Kao et al., 1990) and there are about $10^{4}$ hours in a year.

Where transport requires the calculation of gradients for each tracer, or a few additions, photochemistry demands assembly of total kinetic production and loss terms ( $p$ and 1 ) and hence may entail an order of magnitude more operations. Clearly kinetics can be rate limiting, even if they are advanced at the transport time step, which is likely to be near photolytic restrictions imposed by the diurnal cycle. The authors have been involved in development of chemistry modules specialized for global three dimensional calculations (Kao et al., 1990; Elliott et al., 1993 a through d). The programs make it possible to run kinetics calculations at step sizes in the vicinity of one hour.

\section{A Individual Species Continuity Equations}

An examination of the continuity equations underlying atmospheric kinetics will provide the reader with some insight into various approaches to the global scale problem. The formulas developed here are to some extent a review of Elliott et al. (1993 a and d). We reiterate them as a convenience, and also to establish a context for our computational arguments.

For a single species $s$ inserted into a tracer transport code. we may express continuity as

$\partial \mathrm{s} / \partial \mathrm{t}=-\nabla \cdot \Phi+\mathrm{p}(\mathrm{s})-\mathrm{l}(\mathrm{s})$,

where bold quantities are vectors, $\Phi$ is a flux, and $p$ and $l$ are kinetic production and loss respectively [Brasseur and Solomon. 1984]. The flux may be dissected into its advective components us. where $u$ is the velocity field $u, v$, $w$, and into diffusion terms. The partials with respect to space can also be 
expressed directly [Brasseur and Solomon. 1984; Tson et al, 1988; Kaye and Rood, 1989], as in

$\partial s / \partial t=-(\partial u s / \partial x+\partial v s / \partial y+\partial w s / \partial z)+D+p(s)-1(s)$,

where $\mathrm{D}$ is a generalized diffusion adjustment. The vector $\mathbf{s}$ could just as easily be replaced by the indexed form $\mathbf{s} j$.

Current GCM calculations often rely on spectral techniques [see series Dickinson and Williamson, 1972; Williamson, 1976; Williamson and Temperton 1981; Rasch, 1985 a and b; Rasch and Williamson, 1990 and 1991]. Chemistry is only rarely solved spectrally [Norell, 1986]. Even within the GCM structure, Eulerian translators may be included [Kao et al., 1990]. Here we will use the Eulerian format of a chemical tracer model as an example [Prather et al., 1987; Zimmerman et al. 1989; Kao et al., 1992 and b]. Placement of kinetics into CTMs will often be a first step in creating global chemical simulations [Crutzen and Zimmerman. 1991; Kao et al., 1992 b].

The expedient of time splitting provides a conv enient mechanism for conjugating chemistry and transport. Equations (1) and (2) can be transformed to

$$
\partial s / \partial t=-\nabla \cdot \Phi,
$$

and

$\mathrm{d} s / \mathrm{dt}=\mathrm{p}(\mathrm{s})-\mathrm{l}(\mathrm{s})$,

focussing on dynamics and internal kinetics, respectively. Expressions (3) and (4) dissect full continuity relations into sub-equations pertaining to individual physical processes, which are then solved separately. The same manipulations which lead to them can be performed internally to divide transport into the physical directions, or kinetics into phases. The pros and cons of decoupling operators are weighed against one another by Yanenko (1971). McRae et al. (1982 a and b), and Rood (1987). Chemistry is reduced to an inherently ordinary system, the only independent variable being time.

Either the coupled continuity equations (1) and (2) or the segregated chemistry (4) may be solved using finite differencing. The method of lines reduces the partials of (1)-(3) to ordinary differential equations [Liskovets, 1965: Chang et aL, 1973] so that we may simplify any of (1) through (4) to the form

$\mathrm{ds} / \mathrm{dt}=\mathrm{f}(\mathrm{s})$.

Most of the finite differencing techniques are subsets of the general multistep [Byrne and Hindmarsh, 1987].

$$
s^{t+1}=\sum_{{ }_{b=0}}^{\mathrm{K}_{1}} \alpha_{h} s^{t-h}+\Delta t \sum^{\mathrm{K}_{2}=-1} \beta_{h} f\left(s^{t-h}\right),
$$


where $t$ and $t+1$ are the current and future locations in time. $\Delta t$ is the stcp size. and $\alpha$ and $\beta$ are specific constants.

Equation (6) can be reduced to the most fundamental of all differencing molecules, the forward (explicit) Euler,

$s^{t+1}=s^{t}+\Delta t f\left(s^{t}\right)$,

or to the reverse (implicit) Euler.

$\mathbf{s}^{\mathrm{t}+1}=\mathbf{s}^{\mathrm{t}}+\Delta \mathrm{f}\left(\mathbf{s}^{\mathrm{t}+1}\right)$

or even to combinations of them such as the Crank-Nicholson [Crank and Nicholson, 1947; Toon et al., 1988], $s^{t+1}=s^{t}+\Delta t\left[f\left(s^{t+1}\right)+f\left(s^{t}\right)\right] / 2$.

The latter is better known for applications to pure transport problems. The multistep also leaves room for an adjustable degree of implicitness [Richtmyer, 1957; Turco and Whitten, 1974], or in other words, $s^{t+1}=s^{t}+\Delta t\left[\gamma f\left(s^{t+1}\right)+(1-\gamma) f\left(s^{t}\right)\right]$, where $\gamma$ lies between 0 and 1 . The generalized backward differentiation formulas (BDFs), of which (8) is a prime example, are another subset of (6) [Byrne and Hindmarsh, 1987].

\section{B. Multiple Species Continuity Equations}

To represent three-dimensional situations within which species interact chemically, the continuity and differencing equations must be converted either to a scalar subscripted or a vector format. Some key examples are

$\partial s_{j} / \partial t=-\nabla \cdot \Phi\left(s_{i}\right)+p_{i}(s)-l_{i}(s)$,

$\mathrm{ds} / \mathrm{dt}=\mathrm{p}_{\mathrm{i}}\left(\mathrm{s}_{\mathrm{j}}\right)-\mathrm{l}_{\mathrm{i}}\left(\mathrm{s}_{\mathrm{j}}\right)$,

in which subscripts $i$ and $j$ can vary over all chemical constituents.

$\mathrm{ds}_{\mathrm{k}} / \mathrm{dt}=\mathrm{f}_{\mathrm{k}}(\mathrm{s})$,

in which subscript $k$ can vary over constituents alone, or over constituents and the grid: the full vector statement

$\mathrm{ds} / \mathrm{dt}=\mathrm{f}(\mathrm{s})$

is the equivalent of $(5 \mathrm{~A})$. The finite differences are also readily transposed to vector notation; for example. the forward and reverse Euler, respectively. become

$s^{t+1}=s^{t}+\Delta t f\left(s^{t}\right)$ and 
$s^{t+1}=s^{t}+\Delta t r\left(s^{t}+1\right)$.

The atmospheric chemical ODEs offer an archetypal example of the stiffness dilemma [Curtiss and Hirschfelder, 1952; Gear, 1989]. Techniques for combatting stiffness tiave often relied on matrix inversions and algebraic iterations, which can be extremely costly computationally. One early group of integrators which became standard involved both simultaneously [Gear, 1971; Lapidus et al., 1974: Byrne and Hindmarsh, 1987]. The best known implementation has been the Gear routine [Gear, 1971; Chang et al., 1973; Turco and Whitten, 1974; Wuebbles and Chang, 1975; Hesstvedt et al., 1978]. and it is still finding uses even today [Johnston et al., 1989; Kinnison et al. 1989; Wuebbles et al., 1989; Zinn et al, 1990; Atherton and Penner, 1990l. The Gear algorithm is a linear multistep backward differentiation formula, and so falls under the umbrella of (6) here [Gear, 1971; Byrne and Hindmarsh, 1987]. Weighted information from previous time steps is adopted, but fundamentally implicit differencing leads to a nonlinear algebraic system which must be solved to advance in time. The multiple species reverse Euler is very similar, and has also been extensively applied [Wofsy, 1978; Logan et al., 1978 and 1981; Jacob et al., 1989; Jacob and Wofsy, 1990].

Referring to the equation set we have developed here, the term $f(s)$ in $(5 \mathrm{~A})$ and $(5 \mathrm{~B})$ is necessarily nonlinear if photochemistry is included because of the bimolecular nature of the majority of environmental vapor phase reactions. The chemistries of the atmosphere are driven by solar ultraviolet radiation. which leads to bond breaking and consequently to radicals, which are fleeting. Implicit forms of (6) were used initially to stabilize the radicals, and packages such as the Gear code instituted error controls so that the time step was kept small and adjustable. Iterative matrix inversion was one way to handle the nonlinearities. The implicit Euler is taken as a sample of implicit versions of (6) here, though the overall concepts apply to others [Curtiss and Hirshfelder. 1952; Wofsy, 1978]. With $g$ subsuming $\Delta t$ and $\mathrm{s}^{\mathrm{t}+1}$, (8A) becomes

$g\left(s^{t+1}\right)=s^{t}$

where $s^{t+1}$ are unknown. The most common linearization invokes the Jacobian, $\mathbf{J}$, and is an application of the Taylor series. The Jacobian is a multidimensional derivative, a matrix of partials [McRae et al., 1982 a and b], e.g., $\mathrm{J}=\partial \mathrm{g} / \partial \mathrm{s}$. It leads to the multi-dimensional Newton's method or Newton Raphson. The substitution

$g\left(s^{t+1}\right)=g\left(s^{t}\right)+J \Delta s$

is made into (9), where $\Delta s=s^{t+1}-s^{t}$. The solution may then be iterated to some desired convergence.

Note that the matrix inversions will be expensive. Packaged linear algebra routines [Dongarra et al., 1979: Dongarra and Sorenson, 1986] usually employ Gauss-Jordan elimination, requiring approximately $\mathrm{n}^{3}$ operations to solve (9) and (10) just once, where $\mathrm{n}$ is the number of equations (Oran and Boris. 19811. Given the spacing on our hypothetical global change grid and. 
say, 100 species, $5 \mathrm{~B}$ would involve $10^{3}, 10^{5}$ and $10^{7}$ ODEs in vertical one. zonal two, or full three dimensions; the method of lines yields $10^{3}, 10^{5}$ or $10^{7}$ independent variables. Although early atmospheric chemical models relied heavily on the Gear code, many groups have since rejected it as too slow [Kasting et al. 1984; Chang et al., 1987].

Several workers have attempted to reduce the number of operations required in stiff photochemistry by avoiding matrices [Byrne and Hindmarsh. 1987: Brown, 1987; Brown and Hindmarsh, 1986; Brown and Saad. 1990; Strout et al. 1991]. Matrix-free iterations are utilized, with mathematically objective techniques for sorting array elements [Brown and Hindmarsh, 1986]. Some chemically intuitive integrators are closely related. The backward Euler traditional within the Harvard chemistry group models [Wofsy, 1978; Logan et al., 1978; Jacob et al., 1989; Jacob and Wofsy, 1990] has been converted to the kinetically oriented matrix-free solutions in the interest of speed enhancements [Sillman et al, $1990 \mathrm{a}$ and b; Sillman, 1991]. Time can be advanced semi-implicitly; in the fastest such construction,

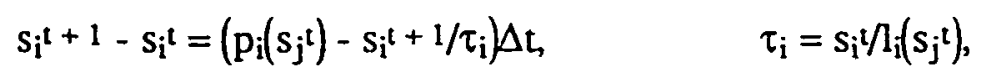

species are completely decoupled from one another. For a single dimension [Richtmyer, 1957] or multiple dimensions with integration in alternating directions [Peaceman and Rachford, 1955; Brasseur et al, 1990], discrete solutions to the partials of equation (1) can be tridiagonal (Richtmyer, 1957; Brasseur et al., 1990. Species are also segregated if $(4 \mathrm{~A})$ is rewritten

$$
\mathrm{ds}_{\mathrm{i}} / \mathrm{dt}=\mathrm{p}_{\mathrm{i}}\left(\mathrm{s}_{\mathrm{j}}^{\mathrm{t}}\right)-\mathrm{s}_{\mathrm{i}} / \tau_{\mathrm{i}}
$$

Analytical solution then gives the standard exponential growth and decay [Hesstvedt et al., 1978; McRae et al., $1982 \mathrm{a}$ and b]

$$
s_{i}{ }^{t+1}=s_{i} t e-\Delta v / \tau_{i}+p_{i}\left(s_{j} t\right) \tau_{i}\left(1-e^{-\Delta v / \tau_{i}}\right) .
$$

The semi-implicit equation (11) can be placed in an instructive algebraic context. Instead of linearizing (8A) or (9) through the Jacobian, we say

$$
f(s)=f\left(s_{j \neq i}, s^{l+1} j=i\right)
$$

which gives,

$$
\mathbf{s}^{\mathrm{t}+1}=\mathbf{s}^{\mathrm{t}}+\Delta \mathrm{tf}\left(\mathbf{s}_{\mathrm{j} \neq \mathrm{i}}^{\mathrm{t}}, \mathbf{s}^{\left.\mathrm{t}+\mathrm{l}_{j}=\mathrm{i}\right)},\right.
$$

or essentially.

$$
\mathrm{s}^{\mathrm{t}+1}=\mathrm{s}^{\mathrm{t}}+\mathrm{p}\left(\mathrm{s}^{\mathrm{t}}\right) \Delta \mathrm{t}-\mathrm{s}^{\mathrm{t}+\mathrm{t}} \Delta \mathrm{t} / \tau_{\mathrm{i}}
$$

A few simple steps lead to the system 
$I s^{i+1}=q$

in which the constant vector $\mathbf{q}$ has the form

$$
q=\left(\mathbf{s}^{\mathrm{t}}+\mathbf{p}\left(\mathbf{s}^{\mathrm{t}}\right) \Delta \mathrm{t}\right) /\left(1+\Delta \mathrm{t} / \tau_{\mathrm{i}}\right)
$$

The algebra resembles that of the Jacobi method, but is positive definite. Iteration is just a matter of success:vely substituting the vector $\mathbf{s}^{t+1}$ for $\mathbf{s}^{\mathbf{t}}$, or even $s_{i}{ }^{t+1}$ for $s_{i}{ }^{i}$ between vector elements [Elliott et al, 1993 a and b].

Iteration and time step control are sometimes preserved in matrix-free solutions to limit error propagation. but there has also been a realization that it only makes sense to impose a certain amount of accuracy upon an atmospheric kinetics calculation [Lapidus and Seinfeld, 1971; Lapidus et al. 1974]. Another step taken by some groups in high dimensionality has been to restrict iteration. Calculations by Sillman [1991] and the Isaksen group in Norway [Hesstvedt et al., 1978; Isaksen and Hov, 1987] fall in this category. In the absence of convergence, concentrations are not evaluated at a unified temporal grid point. Kinetic cancellations are lost and so in turn is mass balance [Shimazaki and Laird, 1970; Turco and Whitten, 1974; Rosenbaum, 1976 and 1977; Shimazaki, 1985; Kaye and Rood. 1989]. Any resulting problems are usually detected by calibration against an integrator of known accuracy [Hesstvedt et al., 1978].

\section{Families}

In parallel with all the individual species photonumerics, family integrations developed. Rapidly interchanging molecules and radicals can be grouped as tracers in and of themselves, with longer collective time constants [Chapman, 1930; Crutzen, 1970]. Families have enabled explicit integration in as high as two dimensions on the global scale [Garcia and Solomon, 1983; Solomon and Garcia 1983; Crutzen and Gidel, 1983; Gidel et al., 1983]. Forward differencing restores mass balance, and the total number of tracers is reduced while time steps lengthen. There is a small cost associated with family groupings; they must be partitioned before production and loss can be constructed. New continuity equations become appropriate.

The family method recognizes that rapidly cycling species act in concert as persistent constituents in many photochemical situations, then assumes steady state to repartition [Chapman, 1930; Crutzen, 1971; Turco and Whitten, 1974 and 1977; Brasseur and Solomon, 1984]. A new array of tracers $c_{n}$ is defined which consists of sums over subsets of $s ; c_{n}=\Sigma_{j} s_{j, n}$, where $j, n$ denotes molecule $j$ within assemblage $n$. Family scale versions of equations presented earlier can then be formulated, with both $n$ and $m$ varying over all groups, as in

$$
\begin{aligned}
& \mathrm{dc}_{\mathrm{r}} / \mathrm{dt}=\mathrm{p}_{\mathrm{n}}\left(s_{\mathrm{j}, \mathrm{m}}\right)-1_{\mathrm{n}}\left(\mathrm{s}_{\mathrm{j}, \mathrm{m}}\right)=\mathrm{f}_{\mathrm{n}}\left(s_{\mathrm{j}, \mathrm{m}}\right), \\
& \mathrm{dc} / \mathrm{dt}=\mathrm{f}(\mathrm{s})
\end{aligned}
$$




$$
\begin{aligned}
& c^{t+1}=c^{t}+\Delta t f\left(s^{t}+1\right), \\
& c_{n}^{t+1}-c_{n}^{t}=\left(p_{n}\left(s_{j, m} m^{t}-c_{n}^{t+1} / \tau_{n}\right) \Delta t ; \tau_{n}=c_{n} t / n_{n}\left(s_{j, m}\right),\right. \\
& c_{n}^{t+1}=c_{n}^{t} e^{-\Delta t / \tau_{n}}+\left(p_{n}\left(s_{j, m}{ }^{t}\right)\right) \tau_{n}\left(1-e^{-\Delta t / n}\right) .
\end{aligned}
$$

Families have enabled marching at convenient sten sizes in a host of detailed one-dimensional photochemical models [e.g., Crutzen, 1971; Turco and Whitten, 1977; Crutzen et al, 19781, and thus far seem to be a method of choice in higher dimensionality as well [e.g., Garcia and Solomon. 1983; Gidel et al. 1983; Kaye and Rood. 1989; Rose and Brasseur, 1989].

Partitioning of assemblages $c_{n}$ into constituents $s_{j, n}$ can be analyzed algebraically. Topological representations of solutions to linear systems can be constructed and understood in or by analogy with Euclidean 2 and 3 space 5 . which are both readily visualizable. In the time split mode for our atmospheric chemical systems, the ODEs integrated are from kinetic systems alone. Linearized versions of implicit forms such as ( $8 A)$ are often employed, and this gives nonhomogeneous algebraic equation sets; the constant vector in the general form

$$
\mathbf{M x}=\mathbf{r}
$$

is nonzero. For the purposes of the photochemist. the vector $\mathbf{x}$ is a set of concentrations for all species $s$, so we are operating in $n$ space where $n$ is the total number of constituents. $\mathbf{M x}=\mathbf{r}$ is a set of equations for objects of dimension $n-1$ in that $n$ space, by analogy with 2 or 3 space, where they would be lines or planes. The shapes are randomly distributed, so that the vector of values which solves them, their intersection, is likely to exist. If the objects were organized in some fashion, intersections might be avoided, but they are not; two lines in 2 space or three planes in 3 space will intersect in a point unless there is some degree of parallelism. Generally in a finite differencing system, parallels do not occur. This means there is probably a unique solution. We can interpret such geometries in terms of formal definitions for solutions to linear algebra problems found by employing Cramer's rule. The solution vector elements are given by

$x_{i}=\operatorname{det} M_{i} / \operatorname{det} M$,

where $\mathbf{M}_{\mathrm{i}}$ has the ith column replaced by $\mathbf{r}$. Usually neither $\operatorname{det} \mathbf{M}$ nor $\operatorname{det} \mathbf{M}_{\mathrm{i}}$ are precisely equal to zero. If $\operatorname{det} M=0$, no unique solution exists. The matrix is singular.

In a number of important circumstances in atmospheric chemistry, homogeneous systems are encountered; the constant vector is exactly 0 . The Jacobian eigenvalue prolem, which enters into analyses of stiffness. is one example [McCrae et al. 1982 a and b]. In n space, a homogeneous algebra set also represents $n$ objects of dimension $n-1$. but all are constrained to pass through the origin. The shapes thus already have one point in common. If they 
have a unique solution, then it is necessarlly trivial. Any other solutions must contain the origin. In 2 and 3 space, for example, the two lines may be identical, or three planes may be rotations around a line, and the solution is aiso a line, through 0 . In vector notation, this line has the form $p=0+\beta p_{o}$. where $\beta$ is a scalar scaling factor, $p$ is a point in $n$ space on the line, and $p_{o}$ is our reference point. In formal solution terms, we can only get nontrivial, or nonunique solutions if $\operatorname{det} M=0$-- if the coefficient matrix is singular. Note also that with Cramer's rule applied, if detM is nonzero, det $M_{i}$ must vanish because $\vec{i}$ is 0 . The trivial answer results. In the eigenvalue problem, $\operatorname{det} M=0$ is polynomial with $n$ solutions. There are $n$ combinations of the (n-1)dimensional objects such that they have nonzero solutions. Each of these combinations corresponds to a vector, the eigenvector, and in 3 or 2 space, it defines the line of intersection.

Now we are in a position to move back into family chemistry. Here 2 and 3 space serve as more than just analogies, because photochemical ensembles often contain only a few members. Family chemistry usually entails the assumption of photochemical equilibrium, or that $d s_{j, n} / d t=0$ and $d s_{n} / d t=0$. Implicit finite differencing gives a homogeneous set. In real kinetic experience, it must have a nontrivial solution, but according to the above, this is only possible if detM $=0$. By virtue of the cyclic nature of the chemistry. zero determinants are often the case. The oxygen family can be cited. Photochemical equilibria for the members ozone and atomic oxygen ${ }^{3} P$ (ignoring $\mathrm{O}^{1} \mathrm{D}$ ) are

$$
\begin{aligned}
& \mathrm{O}_{3}: 0=\mathrm{kQ}_{2} \mathrm{O}-\mathrm{dO}_{3}, \\
& \mathrm{O}: 0=\underline{k \mathrm{Q}_{2} \mathrm{O}+\mathrm{dO}_{3},} \\
& \operatorname{det} \mathbf{M}=\mathrm{kO}_{2} \mathrm{~d}-\mathrm{kO}_{2} \mathrm{~d}=0
\end{aligned}
$$

with kinetic terms comprising the coefficients underlined, and d signifying the photolysis constant. $J$ is a more common choice for the latter, but we wish to avoid nomenclature conflicts with the Jacobian. For the hypothetical interchanging collection $s_{1, n} \rightarrow s_{2, n} \rightarrow s_{3, n} \rightarrow s_{1, n /}$

$$
\begin{aligned}
& s_{1, n}: 0=\frac{-k}{1} s_{1, n}+\underline{l}_{2, n}+\underline{k}_{3} s_{3, n} \\
& s_{2, n}: 0=\underline{k}_{1} s_{1, n}-\underline{k}_{2} s_{2, n}+l s_{3, n} \\
& s_{3, n}: 0=l_{1, n}+\underline{k}_{2} s_{2, n}-\underline{k}_{3} s_{3, n} \\
& \operatorname{det} M=-k s_{1}\left(-k_{2} \cdot-k_{3}\right)-0+k_{3}\left(k_{1} \cdot k_{2}\right)=0
\end{aligned}
$$


In Euclidean 2 and 3 spaces, det $=0$ indicates that the two lines solving the system are identical, or the three planes are rotations around a line. The concentration relationships obtained are ratios, as we know from solving such systems analytically, and they can be expressed as a set of coricentration values. or values for elements of the concentration vector multiplied by the arbitrary scaling factor, which we determine by mass balance.

Chained kinetics also apply, as in the methane oxidation sequence following the methyl radical,

$$
\mathrm{CH}_{3} \mathrm{O} 2(+\mathrm{NO}) \rightarrow \mathrm{CH}_{3} \mathrm{O}\left(+\mathrm{O}_{2}\right) \rightarrow \mathrm{CH}_{2} \mathrm{O}
$$

At photoequilibrium,

$$
\begin{aligned}
& \mathrm{CH}_{3} \mathrm{O}_{2}: 0=k\left(\mathrm{CH}_{4}\right)(\mathrm{OH})-k^{\prime}\left(\mathrm{N} \mathrm{O}^{\circ}\right)\left(\mathrm{C} \mathrm{H}_{3} \mathrm{O}_{2}\right) \\
& \mathrm{CH}_{3} \mathrm{O}: 0=k^{\prime}\left(\mathrm{N} \mathrm{O}^{\circ}\right)\left(\mathrm{CH}_{3} \mathrm{O}_{2}\right)-k^{\prime \prime}\left(\mathrm{O}_{2}\right)\left(\mathrm{CH}_{3} \mathrm{O}\right)
\end{aligned}
$$

but in fact we only use the second equation to partition because families traditionally exclude extra-familial production and because the first does not contain information relating $\mathrm{CH}_{3} \mathrm{O}_{2}$ to $\mathrm{CH}_{3} \mathrm{O}$. The single equation in two unknowns establishes a line in 2 space, through 0 . or, again, just a set of ratios of concentrations.

Families permit increases in step size and a reduction in the number of tracers but can only be integrated explicitly, or in other words, without introducing the nonlinearities leading to the need for matrix inversion and/or iteration, at time scales up to a minute or so. For example, time constants for the stratospheric hydrogen oxide grouping $\mathrm{HO}_{\mathrm{X}}$ and $\mathrm{OH}$ are on the order of minutes [Brasseur and Solomon, 1984], but the species cannot logically be lumped into larger assemblages because they possess a host of source molecules, including water, nitric acid, hydrogen peroxide, and organic oxidations. Since time steps in global three-dimensional tracer transport codes generally are much longer, the family technique is not in and of itself sufficient to circumvent rate limitations by the chemical operator. Several points emerge from this listing of photochemical continuity equations. The chemical operator must avoid large matrices and also iterations. Chang et al. [1987] concluded, for example, that even in the time split mode, matrix inversion would be prohibitive. Sillman and coworkers [Sillman et al., 1990 a and b; Sillman, 1991] have shown that iterations must be dispensed with whether matrices are involved or not. It will also be advantageous to advance chemistry at near the upper limit time step. defined by the diurnal cycle to be about one hour. Many individual species and several traditional families such as $\mathrm{HOx}$ and $\mathrm{CH}_{3} \mathrm{O}_{2} / \mathrm{CH}_{3} \mathrm{O}$ are unstable at hour increments, so that a conflict necessarily arises between achieving speed, accuracy, and mass balance: implicit integration is demanded, but may be conducted in the spirit of equations (11) - (17). The unity of the concentration vector is then lost 
[Isaksen and Hov, 1987; Rose and Brasseur, 1989; Brasseur et al. 1990]. The authors of the present report have been expluring an alternative option. In several models, the conflict has been resolved in part by superimposing mass balance post hoc.

Insteiar of just partitioning at photochemical equilibrium within an assemblage, a family can be distributed into species along a time coordinate. For example, in a hypothetical three-member collection, the time rate of change for species 1 might be expressed in the implicit form

$$
s_{1, n} t+1-s_{1, n} t=\left(P_{e x t}+p s_{2, n} t+1+p s_{3, n} t+1-1 s_{1, n} t+1\right) \Delta t,
$$

where the subscript ext refers to an extra-familial process and $p$ and 1 temporarily designate time constants: $p$ for family internal exchange, 1 for loss of the species at hand. Subsuming $\Delta t$ into matrix coefficients, the family chemistry takes the form

$\left(L-P_{\text {int }}+I\right) S_{n} t+1=P_{8 \times t}+s_{n}^{t}$,

in which $\mathbf{L}$ and $\mathbf{I}$ are diagonal, $\mathbf{P}$ is dense, and int identifies internal production. The family partitioning has now been rendered nonhomogeneous, so that a definite result can be obtained for the constituents. The concentrations $s_{n}{ }^{t+1}$ can be sent through a family version of the forward Euler to restore mass balance, and in our experience, they have a highly stabilizing effect upon it. Bimolecular terms can be linearized to preserve positive definiteness and minimize compromises to atom balance within the family by adopting the substitution

$$
k s_{j, n} s_{j, n}=k\left(s_{j, n}{ }^{t+1} s_{j, n}{ }^{t}+s_{j, n}{ }^{t} s_{j, n}{ }^{t+1}\right) / 2,
$$

when the time tendency is for a species $i \neq j, j^{\prime}$, and the implicit form when is involved in a removal reaction;

$-k s_{j, n} s_{i, n}=-k s_{j, n} s_{i, n}{ }^{t+1}$.

The species levels must occasionally be summed and normalized to c, and calibration is still required.

\section{MASSIVELY PARALLEL COMPUTING OF CHEMISTRY}

The production and loss terms in the photochemical numerics are in fact sums over large numbers of kinetic processes. Most of them will be bimolecular and so will be governed by mass action laws of the forms in (33) and (34). Several multiplications are implied for each. Low dimensionality atmospheric chemistry models may embrace hundreds of species and as many 
as a thousand reactions [Graedel, 1978; Atherton and Penner, 1990: Donaliue and Priun, 1990: Singh and Zinmerman, 1992]. A large fraction aie tropospheric organic oxidation steps. They can be represented in some instances through surrogate strategies [Falls and Seinfeld. 1978; Whitten et al. 1980; Hough, 1988; Gery et al. 1989; Dodge, 1989] but it will still be crucial in chemical/climate simulations to preserve dozens of constituents and well over 100 reactions [Kanakidou et al. 1991; Kanakidou and Crutzen, 1993; Elliott et al., 1993 a through d: Zhao et al., 1993 a and b].

Let us estimate that calculation of the $p$ and 1 in equations 2 through 30 invulves ten multiplicative operations per tracer. Given 100 tracers and 100,000 cells, $10^{12}$ operations per year accrue. At maximum performance rates for current generation vector computers, a few hundred Mflops, such calculations consume hours of CPU time. A time constant for $\mathrm{CO}_{2}$-induced climate change is perhaps 100 years [Houghton et al., 1990 and 1992], the scale often assigned to $\mathrm{CO}_{2}$ doubling. Decadal chemical GCM calculations might thus be marginally feasible on vector machines. However, sensitivity studies will be expected [Stolarski et al., 1978; Thompson and Stewart, 1991], and nature is a high resolution system, so that the numbers of cells and tracers are likely to increase continually. Effort spent on parallelizing chemistry would appear to be justified.

\section{A. Machine Architectures}

Parallel computers differ in important ways from traditional scalar or vector computers. We describe briefly those differences and the problems they present for parallel chemistry calculations.

A simple scalar computer executes each statement of a program one after another (serially). Each iteration of a loop construct is also executed serially. Each of these program statements is translated into machine-level instructions, including fetches from memory, arithmetic or logic operations and storing a result in memory. Modern scalar computers can improve the speed of different components of this process. For example, using a Reduced Instruction Set (RISC) reduces the overhead associated with complicated instructions. Also, fast memory caches have been added to reduce the amount of time it takes to fetch numbers from memory.

Vector machines have made further improvements by recognizing that in many loops, the same operation is performed on a series of operands. In such cases, special vector "pipelines" are filled with the appropriate operands and these pipelines in turn feed the processor with data at the fastest possible rate. Note that because the operands have already been loaded into the pipe. vectorization can only be applied where operands within the loop do not depend on results of previous loop iterations. Vector machines remain inherently serial and statements are still essentially processed one at a time (although some have the capability of performing two or three operations at once). A vector computer simply provides optimal performance in some common constructs like loops.

Parallel computers contain more than one processor and therefore offer the advantage of performing many operations simultaneously. Each processor 
can either perform the same operations on a subset of the lata or can perform entirely different uperations. On massively parallel machines with hundreds or thousands of processors, hundreds or thousands of operations can be performed simultaneously. Parallel machines also provide scalability. If the problem size is doubled, the programmer has the option of doubling the number of processors (up to the machine maximum) to do the larger problem in the same amount of time. At first glance, performing hundreds of operations simultaneously should make massively parallel machines orders of magnitude faster than scalar or vector machines, even when parallel machines make use of processors which are slower individually than their specially-designed vector counterparts. However parallelism brings two additional problems.

First, processors do not know what other processors are doing. If one processor requires data computed by a different processor, either the programmer or compiler must ensure the result is made available where necessary. In some cases, a processor will have to stop work and wait for such a result. If some processors are given less work than others, the result is a load imbalance where a subset of the processors sits idle and waits for others to finish. An extreme example might be a recursive algozithm where only one processor at a time can work on the data and then passes the result to the next processor in line.

Another difference for massively parallel machines is that each processor has its own local memory and cannot directly access a central memory space. If a processor needs data that was computed and stored by a different processor, messages must be sent over a network to retrieve the appropriate data. Communications are often a performance bottleneck for parallel machines either because the overhead for generating such messages is high (high latency) or because the network connecting the processors cannot transfer data at a high enough rate to keep up with the arithmetic on each processor (low bandwidth). On most machines, communications are much faster between between adjacent processors on the network (nearest neighbors) than for processors that are widely separated.

Already some general rules can be inferred for obtaining optimal performance on parallel machines. First, work should be divided as evenly as possible. Second, memory outside the processor's local memory should be avoided as much as possible to minimize communications between processors. If communications are necessary (which is generally the case), one should try to keep them limited to nearest neighbors. In general. this means that whenever possible the data should be distributed in a manner that will maximize the ratio of computation to communication and guarantee nearestneighbor communication.

\section{B. Data Distribution}

As mentioned in the previous section, the most important aspect of parallel programming is the choice of how to distribute data to ensure minimum communications cost and maximum load balancing. Distribution techniques have come to be known as domain decomposition [Glowinski et al. 1983: Keyes and Gropp. 1987; Mankofsky et al. 1988: Chan, 1988; Meurant. 
1988; Keyes, 1989; Ewing, 1991; Brown et al., 1993] and overlapping of grid subdivisions has been a refinement of sume interest [Miki and Takagi. 1984 and 1986; Bjorstadard Widlund, 1989; Chan, 1992].

In atmospheric GCMs the data distribution is relatively straightforward. In a GCM, prognostic fields are generally three-dimensional with two long hnrizontal axes and a relatively short vertical axis. Additionally, radiative transfer along the vertical axis requires many communications between levels. The optinal data layout for a GCM is then to distribute the horizontal axes to provide each processor with enough work and keep the vertical axis local to a processor (serial) to minimize communications.

Atmospheric chemistry data, including species concentrations and reaction rates, will also vary geographically and will depend on fields generated by the GCM. Decomposition of the geographical axes should therefore confoim to that of the GCM with distributed horizontal axes and a serial vertical axis. Maintaining separate arrays for each species or reaction rate is a bit cumbersome. Extending the geographical axes of chemistry arrays with a fourth axis will eliminate this problem and has other advantages as well.

One concerns the automation of the solution to photochemical continuity equations. Nowhere in the atmosphere are kinetic mechanisims sufficiently certain that a set of reactions can be hard wired or frozen into a model. In the stratosphere, half a dozen or so new heterogeneous processes discovered since 1985 have been instrumental in explaining the Antarctic ozone hole [Solomon. 1988; Rodriquez et al, 1989; Hanson and Ravishankara, $1991 \mathrm{a}$ and b; Crutzen et al, 1992; Prather, 1992; Abbatt and Molina, 1992]. They are often represented by gas phase bimolecular equivalents in photochemical simulations [Solomon et al., 1986: McElroy et al. 1986; Jones et al. 1989; Prather, 1992]. In the troposphere, heterogeneous chemistry is only beginning to appear in global models [Levieveld and Crutzen, 1990 and 1991] but is likely to be a source of large uncertainties. Rate constants along organic oxidation sequences are often completely unknown [Trainer et al. 1987: Atkinson et al., 1989; Demore et al., 1990] so that reactions must sometimes be deleted for lack of laboratory kinetics measurements [Thompson and Cicerone, 1986; Cicerone et aL. 1991; Elliott et al. 1994]. It is advisable to maintain flexibility by asking the computer to assemble solutions to the chemistry based on input data lists of species, family definitions and reaction types [Elliott et al., 1993 a through d]. The lists are much more easily altered than hard wired coding.

Such a fourth axis should be kept local to a processor. The axis would be relatively short so would not parallelize well for large numbers of processors. In addition, calculation of production and loss terms may involve many different species and would require many communications if the fourth axis were distributed. Lastly, maintaining all species and rates for a given geographical cell would allow great flexibility in the choice of kinetics integrators.

\section{Programming Models}

Two programming models have evolved for parallel machines. The first is called message-passing because the programmer must insert the appropriate calls to transfer data (messages) between processors. The programmer must 
also determine how the data is to be distributed and must insert barriers to tell the processors when they must wait for a result from another processor.

Message passing was the first method used for programming parallel computers because compilers had not been developed to automate some of these tasks. It has survived because it provides a great deal of flexibility, but at the cost of additional work for the programmer.

A second approach is calied data-parallel. In this case, the data is distributed automatically by the compiler or run-time system and the same or similar operations are performed on all the data simultaneously. This is generally accomplished using array syntax and other features of Fortran 90. If an operation only occurs on a subset of data, a WHERE construct can be used to mask out portions of the data. Communications and reductions are handled through Fortran 90 intrinsic functions like CSHIFT, SUM or MAXVAL. In the data-parallel approach, the underlying machine architecture and data layout is transparent to the prngrammer, although control of the data layout is allowed through compiler directives such as those defined by the High Performance Fortran standard. Such an approach is especially well suited for problems with a fixed grid and nearest neighbor communications. However many operations require arrays to be conformable (same size and distribution) for optimal performance which sometimes results in unnecessary duplication of data and increased memory use.

Atmospheric chemistry can be easily incorporated into either of these two models. Because kinetics calculations do not involve communication between grid cells and we have chosen to distribute only the (horizontal) geographic axes, the kinetics can be performed entirely on processor and no communications are necessary. In a message-passing environment, the kinetics portion would look identical to any existing serial code with the exception of an initialization which distributes the data appropriately. In a data-parallel model, compiler directives would be added for the array layout and a kinetics code written in standard Fortran 90 would run quite efficiently. Operations on large four-dimensional arrays may generate large temporary arrays, but this can be easily prevented by explicitly looping over the fourth index.

\section{Parallel GCM s}

Parallel versions of several atmospheric GCM's already exist or are under devolopment. Among these are the Geophysical Fluid Dynamics Laboratory's SKYHI GCM (Mahlman and Moxim, 1978; Mahlman and Umnscheid, 1987), the Community Climate Model (CCM2) from the National Center for Atmospheric Research, and a UCLA coupled model (Mechoso et al 1993). In addition, a parallel chemical tracer model based on the positive-definite advection schemes of Smolarkiewicz and co-workers (Smolarkiewicz, 1984 and 1991; Margolin and Smolarkiewicz, 1989: Smolarkiewicz and Margolin, 1993) is in progress.

In a time-split scheme, we would rely on the GCM to dynamically advect and diffuse the chemical species, leaving the chemistry package to perform all the local kinetics calculations. SKYHI has been used for tracer transport 
problems (Mahlman and Moxim, 1978) and adding arditional tracers and chemistry could be accomplished quite easily. In the CCM2 model, tracer transport could also be easily incorporated through the semi-Lagrange transport portion of the model.

The addition of atmospheric chemistry would add a significant memory burden on a GCM. A hypothetical global change grid defined here relative to current GCM calculations might contain $10^{5}$ cells (Kao et al.. 1990). The numbers of species and reactons in global chemistry simulation will both soon reach 100 (Elliott et al., 1993 a through d). Under the conditions outlined here it is concelvable that about 10 arrays of $10^{7}$ values each would have to be stored to integrate a kinetic system. Roughly one Gbyte of additional memory would be consumed. Current parallel machines have a maximum memory in the tens of Gbytes. However the full memory is generally not avallable for exclusive production use. Adding chemistry at the modest resolution above would be conceivable, but high resolution simulations would likely exceed the limit on current machines.

\section{SUMIMARY AND CONCLUSION}

Global climate calculations are already saturating the class of modern vector supercomputers with only a few central processing units. Increaser resolution (Mahiman and Umscheid, 1987; Graedel et al., 1993) and inclusion of routines to deal with biogeochemical portions of the terrestrial climate system (Baskin. 1993) will soon demand massively parallel approaches. The atmospheric photchemistry ensemble is intimately linked to climate through the trace greenhouse gases ozone and methane (Fishman et al., 1979; Ramanathan and Dickinson. 1979; Ramanathan et al.. 1987; Crutzen, 1988) and modules for representing it are being attached to global three dimensional transport and GCM frameworks (Kao et al., 1990; Elliott et al., 1993 a through d; Zhao et al., $1993 \mathrm{a}$ and b). Atmospheric kinetics involve dozens of highly interactive tracers and so will accentuate the need for parallel processing of earth system simulations.

In the present text we lay some of the groundwork for addition of atmospheric kinetics packages to GCM and global scale atmospheric models on multiply parallel computers. The discussion is tailored for consumption by the photochemical modelling community. After a review of numerical atmospheric chemistry methods, we examine how kinetics can be implemented on a parallel computer. We concentrate especially on data layout and flexibility and how these can be implemented in various programming models. We conclude that chemistry can be implemented rather easily within existing frameworks of several parallel atmospheric models. However, memory limitations may preclude high resolution studies of global chemistry. 


\section{REFERENCES}

A bbatt J. P. D., \& Molina M. J. (1992). The heterogeneous reaction of HOC I $+\mathrm{HCl}$ on ice and nitric acid trigydrate: recation probabilities and stratospheric implications, Geophys. Res. Lett., 19 (5), 461-464.

Almasi G. S., \& Gottlieb A. (1989), Highly-parallel Computing, Benjamin Cummings Pub., Redwood City, CA.

Andrews D. G., Mahlman J. D., \& Sinclair R. W. (1983), Eliassen-Palm Diagnostics of Wave-Mean Flow Interaction in the GFDL "SKYHI" General Circulation Model, J. Atmos. Sci, 2768.

Atherton C. S., \& Penner J. E. (1990), The effect of biogenic hydrocarbons on the transformation of nitrogen oxddes in the troposphere, J. Geophys. Res., 95, 14027-14038.

Atkinson R., Baulch D. L., Cox R. A., Hampson R. F., Kerr J. A., \& Troe J (1989). Evaluated kinetic and photochemical data for atmospheric chemistry: supplement III, IUPAC subcommittee on gas kinetic data evaluation for atmospheric chemistry. J. Phys. Chem Ref. Data, 18 (2), 8811097.

Baskin Y., (1993), Ecologists put some life into models of a changing world, Science, 259, 1694-1696.

Bjorstad P. E., \& Widlund O. B., (1989). To Overlap or Not to Overlap - A Note on a Domain Decomposition Method for Elliptic Problems, SIAM Journal on Scientific and Statistical Computing, 10 (5), 1053-1061.

Boris J. P., \& Winsor N. K., (1982), Vectorized computation of reactive flow, Parallel Computations, edited by Garry Rodrigue, Academic Press, New York. 173-214.

Boris J. P., \& Winsor N. K., (1982), Vectorized computation of reactive flow, Parallel Computations, edited by Garry Rodrigue, Academic Press, New York, 173-214.

Brasseur G.. \& Solomon S., (1984), Aeronomy of the Middle Atmosphere, $D$. Reideh, Dordrecht.

Brasseur G., Hitchman M. H., Walters S., Dymek M., Falise E., \& Pirre M., (1990). An interactive chemical dynamical radiative two-dimensional model of the middle atmosphere, J. Geophys. Res., 95. 5639-5655. 
Brown D., Clarke J. H. R., Okuda M., \& Yamazakd T., (1993). A Doinain

Decomposition Parallelization Strategy for Molecular-Dyıamics Simulations on Distributed Memory Machines, Computer Physics Communications, 74

(1), 67-80.

Brown P. N., (1987), A local convergence theory for combined inexact Newton finite-difference projection methods, SIAM $J$. Numer. Anal., 24, 407-434.

Brown P. N., \& Hindmarsh A. C., (1986), Reduced storage matrix methods in stiff ODE systems, Appl. Math. and Comput., 31, 40-91.

Brown P. N., \& Saad Y., (1990), Hybrid Krylov methods for non-linear systems of equations, SIAM J. Sci. Stat. Comput., 11, 450-481.

Byrne G. D., \& Hindmarsh A. A., (1987), Stiff ODE solvers: A review of current and coming attractions, J. Comput. Phys., 70, 1-62.

Cess R. D., Zhang M. -H., Potter G. L., Barker H. W., Colman R. A., Dazlich D. A., Del Genio A. D., Esch M., Fraser J. R., Galin V., Gates W. L., Hack J. J., Ingram W. J., Kiehl J. T., Lacis A.A., Le Treut H., Li Z.-X., Liang X. -Z., Mahfouf J. -F., McAvaney B. J, Meleshko V. P., Morcrette J. -J., Randall D. A.. Roeckner E., Royer J. -F., Sokolov A. P., Sporyshev P. V., Taylor K. E., Wang W. -C.. \& Wetherald R. T.. (1993). Uncertainties in Carbon Dioxide Radiative Forcing in Atmospheric General Circulation Models, Sci., 262, 1252.

Chan T. F., (1992), On the Relationship Between Overlapping and Nonoverlapping Domain Decomposition Methods, SIAM Joumal on Matrix Analysis and Applications, 13 (2), 663-670

Chan T. F., (1988), Domain Decomposition Algorithms and Computational Fluid-Dynamics, International Joumal of Supercomputer Applications, 2 (4). 72-83.

Chang J. S., Brost R. A., Isaksen I. S. A., Madronich S., Middleton P., Stockwell W. R., \& Walcek C. J., (1987), A three dimensional eulerian acid deposition model: Physical concepts and formulation, J. Geophys. Res.. 92. 14681-14700.

Chang J. S., Hindmarsh A. C., \& Madsen N. K., (1973), Simulation of chemical kinetics transport in the stratosphere. Stiff Differential Systems, edited by R. S. Willoughby, Plenum Press, New York.

Chapman S., (1930), A theory of upper atmospheric ozone. Mem. Roy. Meteorol. Soc., 3, 103-117.

Cicerone R. J.. Elliott S., \& Turco R. P., (1991), Reduced antarcitic ozone depletions in a model with hydrocarbon injections. Science, 254, 11911194. 
Crank J., \& Nicholson P., (1947), A practical method for numerical evaluation of solutions of partial differential equations of the heat conduction type. Proc. of the Cambridge Philosophical Soc.. 43, 50-67.

Crutzen P. J., (1970). The influence of nitrogen oxddes on the atmospheric ozone content, Quarterly J. Roy. Met. Soc.. 96. 320-333.

Crutzen P. J., (1971), Ozone production rates in an oxygen-hydrogennitrogen oxide atmosphere, J. Geophys. Res., 76, $7311-7327$.

Crutzen P. J., (1988), Tropospheric ozone: Arı overview, In Tropospheric Ozone, edited by I. S. A. Isaksen, D. Ridel, Dordrecht, 3-32.

Crutzen P. J., \& Gidel L. T., (1983), A two dimensional photochemical model of the atmosphere 2. The tropospheric budgets of the anthropogenic chlorocarbons $\mathrm{CO}, \mathrm{CH}_{4}, \mathrm{CH}_{3} \mathrm{Cl}$ and the effect of various $\mathrm{NO}_{\mathrm{x}}$ sources on tropospheric ozone, J. Geophys. Res., 88, 6ô41-6661.

Crutzen P. J., \& Zimmermann P. H., (1991), The changing photochemistry of the troposphere, Tellus, 43AB, 136-151.

Crutzen P. J., Isaksen I. S. A., \& McAfee J. R., ( 1978). The impact of the chlorocarbon industry on the ozone layer, J. Geophys. Res., 83, 345-362.

Crutzen P. J., Muller R., Bruhl Ch., \& Peter Th., (1992), On the potential importance of the gas phase reaction $\mathrm{CH}_{3} \mathrm{O}_{2}+\mathrm{ClO} \rightarrow \mathrm{C} 100+\mathrm{CH}_{3} \mathrm{O}$ and the heterogeneous reaction $\mathrm{HOCl}+\mathrm{HCl} \rightarrow \mathrm{H}_{2} \mathrm{O}+\mathrm{Cl}_{2}$ in "ozone hole" chemistry, Geophys. Res. Lett., 19 (11), 1113-1116.

Curtiss C. F.. \& Hirschfelder J. O., ( 1952), Integration of stiff equations, Proc. NAS, 38, 235-243.

Demore W. B., Sander S. P.,Golden D. M., Molina M. J., Hampson R. F., Kurylo M. J., Howard C. J., \& Ravishankara A. R., (1990), Chemical kinetics and photochemical data for use in stratospheric modeling. Evaluation Number 9, Jet Propulsion Laboratory Publ. 90-1.

Dickinson R. E., \& Williamson D. L., (1972), Free oscillations of a discrete stratified fluid with application to numerical weather prediction, J. Atomos. Sci., 29, 123-143.

Dodge M. C., (1989). A comparison of three photochemical oxidant mechanisms, J. Geophys. Res., 94 (D4), 5121-5136.

Donahue N. M., \& Prinn R. G., (1990), Non-methane hydrocarbon chemistry in the remote marine boundary layer, J. Geophys. Res., 95, 18387-18411. 
Dongarra J. J., \& Sorensen D. C., (1986), Linear algebra on highperformance computers, Rpt ANL-86-2, Argonne National Laboratury, Argonne, Illinois.

Dongarra J. J., Moler C. B., Bunch J. R., \& Stewart G. W., (1979), The Society for Industrial and Applied Mathematics, LINPAC User's Guide, Philadelphia.

Dukowicz J. K., Smith R. D.. \& Malone R. C., (1993), A reformulation arid implementation of the Bryan Cox Semtner ocean model on the connection machine, J. Atmos. Oceanic Tech., 16 (2).

Elliott S., Cicerone R. J., Turco R. P., Drdla K., \& Tabazadeh A., (1994). Influence of the heterogeneous reaction $\mathrm{HCl}+\mathrm{HOCl}$ on an ozone hole model with hydrocarbon additions, J. Geophys. Res., in press.

Elliott S., Kao C. Y. J, Turco R. P., \& Zhao X. P.. (1993a), Kinetics programs for simulation of tropospheric photochemistry on the global scale, Los Alamos National Laboratory Technical Report LA-12539-MS.

Elliott S., Turco R. P., \& Jacobson M. Z., (1993b), Mass conserving numerical projections for stabilizing stiff photochemical systems at long time step. Comput. Chem., 17 (1), 91-102.

Elliott S., Turco R. P., Zhao X. P., Kao C. Y. J., \& Shen M., (1993d), Photochemical numerics for global scale modelling: fidelity and GCM testing submitted to $J$. Applied Meteorology.

Elliott S., Turco R. P., Zhao X. P., Shen M., \& Kao C. Y. J., (1993c), Efficient and modular kinetics packages for global scale photochemical modelling. In The Role of Meteorology in Managing the Environment of the Nineties, edited by Amiram Roffman, AWMA, Pittsburgh, 73-84.

Ewing R. E., (1991), Application of Domain Decomposition Techniques in Large-Scale Fluid-Flow Problems, Applied Numberical Mathematics, 8 (4-5), 375-388.

Falls A. H., \& Seinfeld J. H., (1978), Continued development of a kinetic mechanism for photochemical smog, Environ. Sci. Tech., 12. (13), 13981406.

Fels S. B., Mahlman J. D., Schwarzkopf M. D., \& Sinclair R. W., (1980), Stratospheric Sensitivity to Perturbations in Ozone and Carbon Dioxide: Radiative and Dynamical Response, J. Geophys. Res., 2265.

Fishman J., Solomon S., \& Crutzen P. J., (1979), Observational and theoretical evidence in support of a significant in-situ photochemical source of tropospheric ozone, Tellus, 32, 456-463.

Flynn M. J., (1966), Very high speed computing systems, Proc. IEEE, 54, 47-63. 
Garcia R. R., \& Solomon S.. (1983), A numerical mociel of the zonally averaged dynamical and chemical structure of the middle atmosphere, $J$. Geophys. Res., 88, 1379-1400.

Gear C. W., (1971a), Numerical Initial Value Problems in Ordinary Differential Equations, Prentice Hall, Englewood Cliffs, New Jersey.

Gear C. W., (1971b), The automatic integration of stiff ordinary differential equations, Information Processing. 68, 187-193.

Gery M. W., Whitten G. Z., Killus J. P.. \& Dodge M. C., (1989), A photochemical kinetics mechanism for urban and regional scale computer modelling, J. Geophys. Res., 94 (D10), 12925-12956.

Gidel L. T., Crutzen P. J., \& Fishman J., (1983), A two dimensional photochemical model of the atmosphere 1: Chlorocarbon emissions and their effect on stratospheric ozone, J. Geophys. Res., 88, 6622-6640.

Glowinski R., Dinh Q. V., \& Periaux J., (1983), Domain Decomposition Methods for Non-Linear Problems in Fluid-Dynamics, Comput. Meth. App. Mech. Engineer. 40 (1), 27-109.

Graedel T. E., (1978), Chemical Compounds in the Atmosphere, Academic Press, New York.

Graedel T. E.. Bates T. S., Bouwman A. F., Cunnold D., Dignon J., Fjung I., Jacob D. J.. Lamb B. K., Logan J. A., Marland G., Middleton P., Pacyna J. M.. Placet M., \& Veldt C.. (1993), A compilation of inventories of emissions to the atmosphere, Global Biogeochem. Cycles, 7 (1), 1-26.

Hanson D. R. \& Ravishankara A. R., (1991b), The reaction probabilities of $\mathrm{ClONO}_{2}$ and $\mathrm{N}_{2} \mathrm{O}_{5}$ on 40 to $70 \%$ sulfuric acid solutions, J. Geophys. Res., 96 (D9), 17, 307-17314.

Hanson D. R. , \& Ravishankara A. R., (1991a). The reaction probabilities of $\mathrm{ClONO}_{2}$ and $\mathrm{N}_{2} \mathrm{O}_{5}$ on polar stratospheric cloud materials, J. Geophys. Res., 96. 5081-5090.

Hesstvedt R., Hov O., \& Isaksen I. S. A., (1978), Quasi steady state approximations in air pollution modelling: Comparison of two numerical schemes for oxidant prediction, Int. J. Chem. Kin., 10, 971-994.

Hough A. M., (1988), An intercomparison of mechanisms for the production of photochemical oxidants, J. Geophys. Res., 93 (D4), 3789-3812.

Houghton J. T., Callander B. A., \& Varney S. K.. (1992), Climate Change 1992: The Supplementary Report to the IPCC Scientific Assessment. Cambridge University Press. Cambridge. 
Houghton J. T., Jenkins G. J., \& Ephraums J. J., (1990), Climate Change: The IPCC Scientific Assessment, Cambridge University Press, Cambridge.

Isaksen I. S. A, \& Hov O., (1987), Calculation of trends in the tropospheric concentration of ozone, hydroxyl, carbon monoxide, methane and $\mathrm{NO}_{\mathrm{x}}$. Tellus, 39B, 271-285.

Jacob D. J., \& Wofsy S. C., (1990), Budgets of reactive nitrogen. hydrocarbons, and ozone over the Amazon forest during the wet season, $J$. Geophys, Res., 95, 16737-16754.

Jacob D. J., Sillman S., Logan J. A. , \& Wofsy S. C., (1989), Least independent variables method for simulation of tropospheric ozone, J. Geophys. Res., 94, 8497-8509.

Johnston H. S., Kinnison D. E., \& Wuebbles D. J., (1989), Nitrogen oxides from high-altitude aircraft: An update of potential effects on ozone, $J$. Geophys. Res., 94, (D13), 16351-16363.

Jones R. J., Austin J., McKenna D. S., Anderson J. G., Fahey D. W., Farmer C. B., Heidt L. E., Kelly K. K., Murphy D. M., Proffitt M. H., Tuck A. F., \& Vedder J. F., (1989), Lagrangian photochemical modelling studies of the 1987 antarctic spring vortex, 1. Comparison with AAOE observations, J. Geophys. Res., 94, 11529-11558.

Kanakidou M., \& Crutzen P. J., (1993), Scale problems in global tropospheric chemistry modelling: comparison of results obtained with a three dimensional model. adopting longitudinally uniform and varying emissions of NOx and NMHC. Chemosphere, 26, 787-801.

Kanakidou M., Singh H. B., Valentin K. M., \& Crutzen P. J., (1991), A twodimensional study of ethane and propane oxidation in the troposphere, $J$. Geophys. Res., 96 (D8), 15395-15413.

Kao C. Y. J., Glatzmaier G. A., Malone R. C., \& Turco R. P., (1990), Global three dimensional simulations of ozone depletion under postwar conditions. J. Geophys. Res., 95, 22495-22512.

Kao C. Y. J. Tie X., \& Mroz E., (1992b), Simulations of greenhouse trace gases using the Los Alamos Chemical Tracer Model. American Institute of Physics Conference Proc. Series on Global Climate Change, 134-139.

Kao C. Y. J., Tie X., Mroz E.. Cunnold D., \& Alyea F.. (1992a). Simulations of global CFC-11 using the Los Alamos Chemical Tracer Model, J. Geophys. Res., in press. 
Kasting J. F., Pollack J. B., \& Crisp D., (1984). Effects of high carbon dioxide levels on surface temperature and atmospheric oxidation stare of the early earth, J. Atmos. Chem., 1, 403-408.

Kaye J. A.. \& Rood R. B.. (1989), Chemistry and transport in a 'hree dimensional stratospheric model: Chlorine species during a simulated stratospheric warming, J. Geophys. Res., 94, 1057-1083.

Keyes D. E, \& Gropp W. D.. (1987), A Comparison of Domain Decomposition Techniques for Elliptic Partial-Differential Equations and Their Parallel Implementation, SIAM Journal on Scientific and Statistical Computing, 8 (2), S166-\$202.

Keyes D. E.. (1989), Domain Decomposition Methods for the Parallel Computation of Reacting Flows, Comput. Phys. Comm. 53 (1-3), 181-200.

Kinnison D., Johnston H., \& Wuebbles D. J., (1989), Sensitivity study of global ozone to Nox emissions from aircraft, Ozone in the Atinosphere, eds R. D. Bojkov and P. Fabian, A. Deepak, Hampton, VA.

Lapidus L., \& Seinfeld J. H., (1971), Numerical Solutions of Oridinary Differential Equations, Academic Press, New York.

Lapidus L., Aiken R. C., \& Liu Y. A., (1974), The occurrence and numerical solution of physical and chemical systems having widely varying time constants, Stiff Differential Systems, edited by R. S. Willoughby, Plenum Press, New York.

Lelieveld J.. \& Crutzen P. J.. (1990). Influences of cloud photochemical processes on tropospheric ozone, Nature, 343, 227-233.

Lelieveld J., \& Crutzen P. J.. (1991), The role of clouds in tropospheric chemistry, J. Atmos. Chem. 12, 229-267.

Levesque J. M., \& Williamson J. W., (1989), A Guidebook to FORTRAN on Supercomputers. Academic Press, New York.

Liskovets O. A., (1965), The method of lines, Differential Equations, 1. 1662-1678.

Logan J. A., Prather M. J., Wofsy S. C., \& McElroy M. B., (1978), Atmospheric chemistry: Response to human influence, Philos. Trans. R. Soc. London Ser. A., 290, 187-234.

Logan J. A., Prather M. J., Wofsy S. C., McElroy M. B., (1981), Tropospheric chemistry: A global perspective, J. Geophys. Res., 86, 7210-7254. 
Mahlman J. D., \& Moxim W. J., (1977), Tracer Simulation Using a Global General Circulation Model: Results from a Midlatitude Instantaneous Source Experiment, J. Atmos. Sci., 35, 1340.

Mahlman J. D., \& Umscheid L. J., ( 1987), Comprehensive modeling of the middle atmosphere: The influence of horizontal resolution, in Transport Process in the Middle Atmosphere, edited by G. Viscontl and R. Garcia, D. Ridel, Dordrecht, 251-256.

Malone R. C., Auer L. H., Glatzmaier G. A., Wood M. C., \& Toon O. B., (1986), Nuclear Winter, Three-dimensional simulations including interactive transport, scavenging, and solar heating of smoke. J. Geophys. Res., 91, 1039-1053.

Mankofsky A, Ko K, Seftor J. L., Mondelli A. A., Nielsen D. E., Moura J., Brandon S. T., Drobot A. T., Dyer K. M., Almonetti W., \& Chang C. L., (1988), Domain Decomposition and Particle Pushing for Multiprocessing Computers, Comput. Phys. Comm., 48 (1), 155-165.

Margolin L. G., \& Smolarkiewicz P. K., (1989), Antidiffusive Velocities for multipass Doner Cell Advection, Los Alamos National Laboratory UCID21866.

McElroy M. B., Salawitch R. J., Wofsy S. C., \& Logan J. A., (1986), Reductions of antarctic ozone due to synergistic interactions of chlorine and bromine, Nature, 321, 759-762.

McRae G. J., Goodin W. R., \& Seinfeld J. H., (1982a). Development of a second generation mathematical model for urban air pollution I. Model formulation. Atmos. Environ., 16, 679-696.

McRae G. J., Goodin W. R., \& Seinfeld J. H., (1982b), Numerical solution of the atmospheric diffusion equation for chemically reacting flows, J. Comput. Phys., 45, 1-42.

Meurant G., (1988), Domain Decomposition Methods for Partial-Differential Equations on Parallel Computers, Int . J. Supercomput. App., 2 (4), 5-12.

Mechoso, C.R., Ma, C.-C., Farrara, J.D., Spahr, J.A. \& Moore, R.W.. (1993). Parallelization and Distribution of a Coupled Atmosphere-Ocean General Circulation Model, Monthly Weather Rev., 121, 2062.

Miki K. \& Takagi T., (1984), A Domain Decomposition and Overlapping Method for the Generation of 3-Dimensional Boundary-Fitted Coordinate Systems, J. Comp. Phys., 53 (2), 319-330.

Miki K. \& Takagi T., (1986), Numerical-Solution of Poisson Equation with Arbitrarily Shaped Boundaries Using a Domain Decomposition and Overlapping Technique. Journal of Computational Physics, 67 (2), 263-278. 
Miyahara S., Hayashi Y., \& Mahlman J. D., (1985). Interactions between Gravity Waves and Planetary-Scale Flow Simulated by the GFDL "SKYHI" General Circulation Model, J. Atmos, Sci., 43 (17), 1844.

Norelli F., (1986), Improving Reactor Kinetics Calculations by Spectral Methods. RT/VEL/86/2, Comitato Nazionale per la Ricerca e per lo Sviluppo dell'Energia Nucleare e delle Energie Alternative.

Oran E. S., \& Boris J. P., (1981), Detailed modelling of combustion systems, Prog. Energy Combust. Sci., 7, 1-72.

Peaceman D. W., \& Rachford H. H., (1955), The numerical solution of parabolic and elliptic differential equations. J. Soc. Indust. Appl. Math. 3 , $28-41$.

Pitcher E. J., Malone R. C., Ramanathan V., Blackman M. L., Puri K., \& Bourke W.. (1983), January and July simulations with a spectral general circulation model. J. Atomos. Sci., 40, 631-642.

Prather M. J., (1992), More rapid polar ozone depletion through the reaction of HOCI with HCI on polar stratospheric clouds, Nature, 355, 534537.

Prather M. J., McElroy M. B., Wofsy S. C., Russell G., \& Rind D., (1987), Chemistry of the global troposphere: Fluorocarbons as tracers of air motion, J. Geophys. Res., 92, 6579-6613.

Ramanathan V.. (1988). The radiative and climatic consequences of the changing atmospheric composition of trace gases, in The Changing Atmosphere, edited by F. S. Rowland and I. S. A. Isaksen, John Wiley and Sons. 159-186.

Ramanathan V., \& Dickinson R. E., (1979). The role of stratospheric ozone in the zonal and seasonal radiative energy balance of the earth-troposphere system. J. Atmos. Sci., 36, 1084-1 104.

Ramanathan V., Callis L., Cess R., Hansen J., Isaksen I. S. A.,Kuhn W., Lacis A., Luther F., Mahlman J., Reck R., \& Schlesinger M., (1987), Climate chemical interactions and effects of changing atmospheric trace gases, Rev. Geophys., 25, 1441-1482.

Ramanathan V., Pitcher E. J., Malone R. C., \& Blackman M. L., (1983), The response of a spectral general circulation model to improvements in radiative processes. J. Atmos. Sci. 40, 605-630.

Rasch P. J. \& Williamson D. L., ( 1991), The sensitivity of a general circulation model climate to the moisture transport formulation, J. Geophys. Res.. 96 (D7), 13123-13137. 
Rasch P. J., (1985a), Developments in normal mode initialization: I. A simple interpretation for norman mode initialization, Month'y Weather Rev., 113, 1746-1752.

Rasch P. J.. (1985b), Developments in normal mode initialization: II. A new method and its comparison with currently used schemes. IMonthly Weather Rev., 113, 1753-1770.

Rasch P. J.. \& Williamson D. L., (1990), Computational aspects of moisture transport in global models of the atmosphere, GJR Meteor. Soc.. 116, 10711090.

Richtmyer R. D.. (1957). Difference Methods for Initial Value Problems, Inerscience, New York.

Rodriguez J. M., Lo M. K. W.. Aze N. D., Pierce S. D., Andrson J. G., Fahey D. W., Jakoubek R., Kelly K., Mount G. H., Proffitt M. H., Ravishankara A. R. Schmeltekopf A. L., Tuck A. F., Wahner A., Farmer C. B., Toon G. C., Coffey M. T., Heidt L. E., Mankin W. G., Chan K. R., Starr W. L., Vedder J. F., Browell E. V., \& McCormick M. P., (1989), Nitrogen and halogen species in the spring antarctic stratosphere: Comparison of models with AAOE observations, $J$. Geophys. Res., 94 (D14), 16683-16703.

Rood R. B., (1987). Numerical advection algorithms and their role in atmospheric transport and chemistry models, Rev. Geophys., 25, 71-100.

Rose K., \& Brasseur G., (1989), A three-dimensional model of chemically active trace species in the middle atmosphere during disturbed winter conditions, J. Geophys. Res., 94, 16387-16403.

Rosenbaum J. S., (1976), Conservation properties of numerical integration methods for systems of ordinary differential equations, J. Comput. Phys.. 20. 259-267.

Rosenbaum J. S., (1977). Consevation properties for numerical integration methods for systems of differential equations 2., J. Phys. Chem., 81, 23622370 .

Shimazaki T., (1985), Minor Constituents in the Middle Atmosphere, $D$. Reidel, Dordrecht.

Shimazaki T., \& Laird A. R., (1970), A model calculation of the diumal variation in minor neutral constituents in the mesosphere and lower thermosphere including transport effects. J. Geophys. Res.. 75, 3221-3235.

Sillman S., (1991), A numerical solution for the equations of tropospheric chemistry based on an analysis of sources and sinks of odd hydrogen. $J$. Geophys. Res., 96 (DI1), 20735-20744. 
Sillman S.. Logan J. A., \& Wofsy S. C., (1990a), A regional scale model for ozone in the United States with subgrid representation of urban and power plant plumes, J. Geophys. Res., 95 (D5), 5731-5748.

Sillman S., Logan J. A., \& Wofsy S. C., (1990b). The sensitivity of ozone to nitrogen oxides and hydrocarbons in regional ozone episodes, J. Geophys. Res., 95 (D2), 1837-1851.

Singh H. B., \& Zimmerman P., (1992), Atmosphenc distribution and sources of non-methane hydrocarbons, in Gaseous Pollutants: Characterization and cycling, cdited by J. O. Nriagu, John Wiley and Sons, 177-235.

Smith R. D., Dukowicz J. K., \& Malone R. C., (1992), Parallel ocean general circulation modeling, Physica D, 60, 38-61.

Smolarkiewicz P. K.. (1984), A fully multi-dimensional positive definite advecion transport algorithm with small implicit diffusion, J. Comput. Phys., 54. 325-362.

Smolarkiewicz P. K., \& Margolin L. G., (1993), On forward in time differencing for fluids: extension to a curvilinear fromework, Monthly Weather Rev., 121 (6), 1847-1859.

Solomon S., (1988), The mystery of the antarctic ozone hole, Rev. Geophys., 26 (1). 131-148.

Solomon S., \& Garcia R. R., (1983), Numerical modeling of the dynamical and chemical structure of the middle atmosphere, Eur. Space Agncy ISpec. Publ.) ESA SP-183, 117-122.

Solomon S., Garcia R. R., Rowland F. S., \& Wuebbles D. J., (1986), On the depletion of antarctic ozone, Nature, 321, 755-757.

Stolarski R. S., Butler D. M., \& Rundel R. D., (1978), Uncertainty propagation in a stratospheric model II. Monte Carlo analysis of imprecisions due to reaction rates, $J$ Geophys. Res., 83, 3074-3078.

Strout R. E., McGraw J. R., \& Hindmarsh A. C., (1991), An examination of the conversion of software to multiprocessors, J. Parallel and Distributed Comput., 13, 1-16.

Thompson A. M., (1992). The oxidizing capacity of the earth's atmosphere: Probable past and future changes, Science, 256, $1157-1165$.

Thompson A. M., \& Cicerone R. J., (1986), Possible perturbations to atmospheric $\mathrm{CO} . \mathrm{CH}_{4}$ and $\mathrm{OH}, J$. Geophys. Res., 91 (DIO), 10852-10864. 
Thompson A. M., \& Stewart R. W.. (1991), Effect of chemical uncertaincies on calculated constituents in a tropospheric photochemical mociel, $J$. Geophys. Res., 96 (D7). 13089-13108.

Toon O. B., Turco R. P., Westyhal D., Malone R., \& Liu M. S.. (1988). A multidimensional model frr aerosols: Description of computational analogs, J. Atmos. Sci. 45, 2123-2143.

Turco R. P., \& Whitten R. C., (1977), The NASA Ames Research Center One and Two Dimensional Stratcspheric Models Part 1: The one dimensionai model, NASA Tech. Publ. TP-1002.

Turco, R. P. \& Whitten R. C.. (1974). A comparison of several computational techniques for solving some common aeronomic problems, J. Geophys. Res., 79, 3179-3185.

Whitten G. Z., Hogo H., \& Killus J. P., (1980), The carbon bond mechanism: A condensed kinetic mechanism for photochemical smog. Environ. Sci. Tech., 14 (6), 690-700.

Williamson D. L., (1976), Normal mode initialization procedure applied to forecasts with the global shallow water equations, Monthly Weather Rev.. 104, 195-206.

Williamson D. L., \& Temperton C.. (1981), Normal mode initialization for a multi-level grid-point model II.: Nonlinear aspects, Monthly Weather Rev., 109, 744-757.

Wofsy S. C., (1978), Temporal and latitudinal variations of stratospheric trace gases: A critical comparison between theory and experiment, $J$. Geophys. Res., 83, 364-378.

Wuebbles D. J., \& Chang J. S., (1975), Sensitivity of time-varying parameters in stratospheric modelling. J. Geophys. Res., 80, 2637-3642.

Yanenko N. A., (1971), The Method of Fractional Steps, Springer-Verlag. Germany, 160.

Zhao X. P., Turco R. P., \& Lin R.. (1993a), Photodissociation parameterization for stratospheric three dimensional modelling, submitted to J. Geophys. Res.

Zhao X. P., Turco R. P., Kao C. Y. J., Elliott S., \& Newman M., (1993b), An interactive chemical dynamical radiative three dimensional model of the lower stratosphere, EOS Trans. AGU. Fall Meeting.

Zimmermann P. H., Feichter J., Rath H. K.. Crutzen P. J.. \& Weiss W., (1989), A global three-dimensional source-receptor model investigation using krypton-85. Atmos. Environ., 23, 25-35. 